\title{
EFFECT OF SEPARATION DISTANCE ON CAVITATION EROSION OF VIBRATORY AND STATIONARY SPECIMENS IN A VIBRATORY FACILITY
}

KINYA KIKUCHI* and FREDERICK G. HAMMITT

Mechanical Engineering and Applied Mechanics Department, University of Michigan, Ann Arbor, MI 48109-2121 (U.S.A.)

(Received July 4, 1984; accepted January 18, 1985)

\section{Summary}

Vibratory cavitation erosion with vibratory and stationary specimens is studied for three materials in tap water at room temperature. The separation distance is varied from 0.127 to $6.096 \mathrm{~mm}$. Test materials were commercially pure lead, soft (1100-0) aluminum and type 316 stainless steel. The double-horn amplitude was $58.4 \mu \mathrm{m}\left(2.3 \times 10^{-3}\right.$ in) in a $20 \mathrm{kHz}$ facility. The total duration of all tests was $10 \mathrm{~min}$.

The weight loss of both vibratory and stationary specimens of course depends on materials. The weight loss of stationary specimens is best correlated as a function of the reciprocal of the separation distance.

\section{Introduction}

Cavitation erosion of stationary specimens using an otherwise standard vibratory facility was first reported by Endo et al. [1], and this system has been studied since by several researchers (see for example refs. 2 - 4). It is useful for studying materials which cannot be tested with the conventional system because of the high horn accelerations. Unusual materials, e.g. rocks [5], have been tested. The system is also useful for modelling close-clearance geometries such as seals and bearings.

Three materials are studied in the present paper: commercially pure lead, soft aluminum (1100-O) and type 316 stainless steel. For the tests these are arranged in different material "pairs". The test materials thus include two which are very weak (lead and 1100-O aluminum), and one which is highly resistant to cavitation erosion (316 stainless steel). This material is often used in prototype machines.

*Present address: Faculty of Engineering, Tohoku Gakuin University, Tagajo, Miyagi 985, Japan. 


\section{Experimental facility, specimens and conditions}

\subsection{Test facility, specimens and test conditions}

Figure 1 is a schematic diagram of the vibratory facility, including the power amplifier, transducer-horn assembly, test specimens and cavitation vessel, and Fig. 2 is a photograph of the facility. Figure 3 is a drawing of the test specimens. Table 1 lists materials and experimental conditions, including approximate mechanical properties.

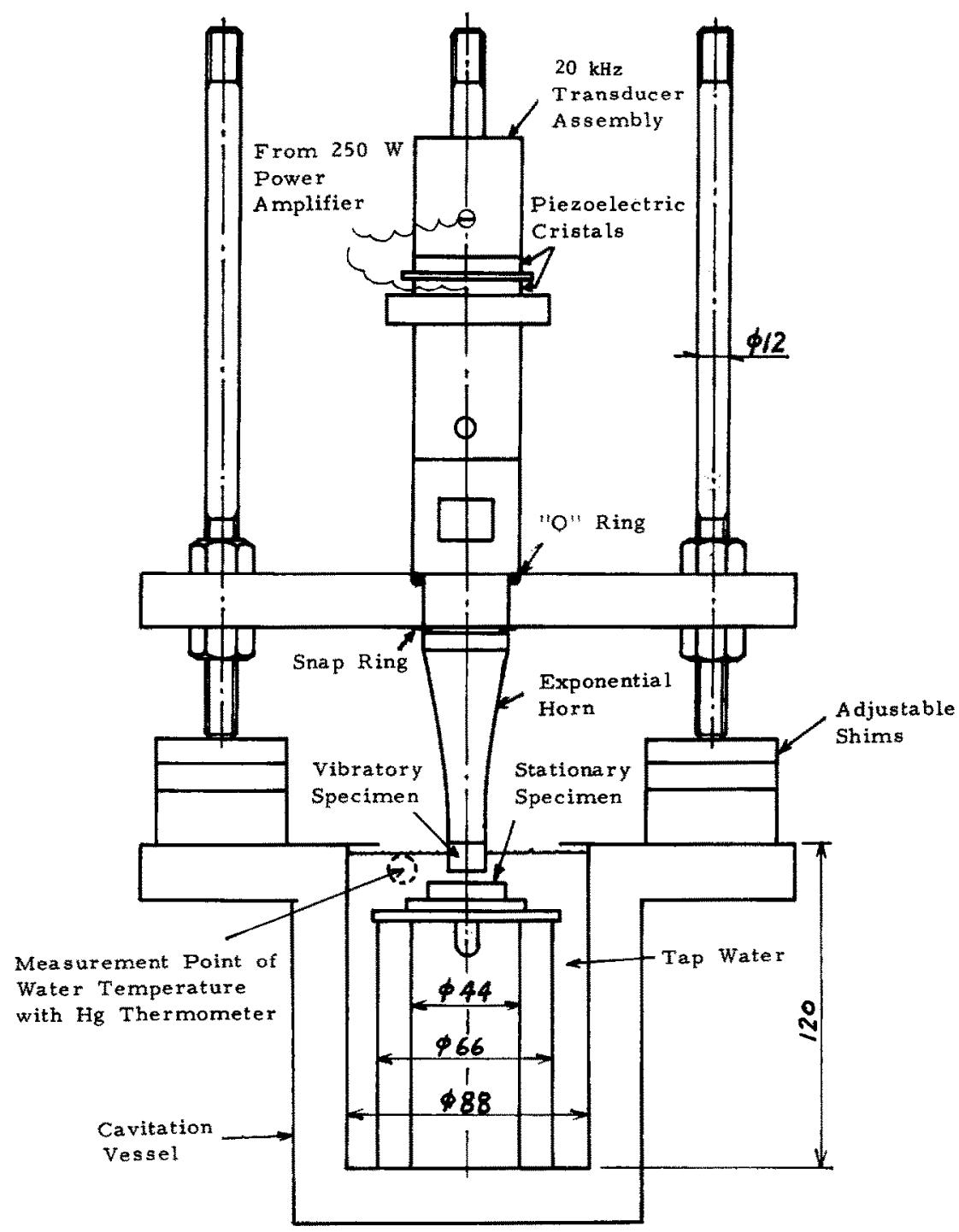

Fig. 1. Vibratory facility (dimensions in millimeters). 


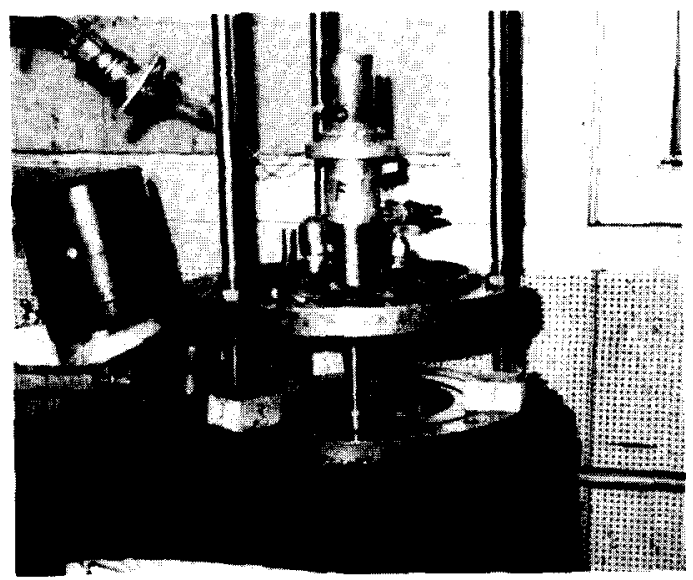

Fig. 2. Photograph of the facility.

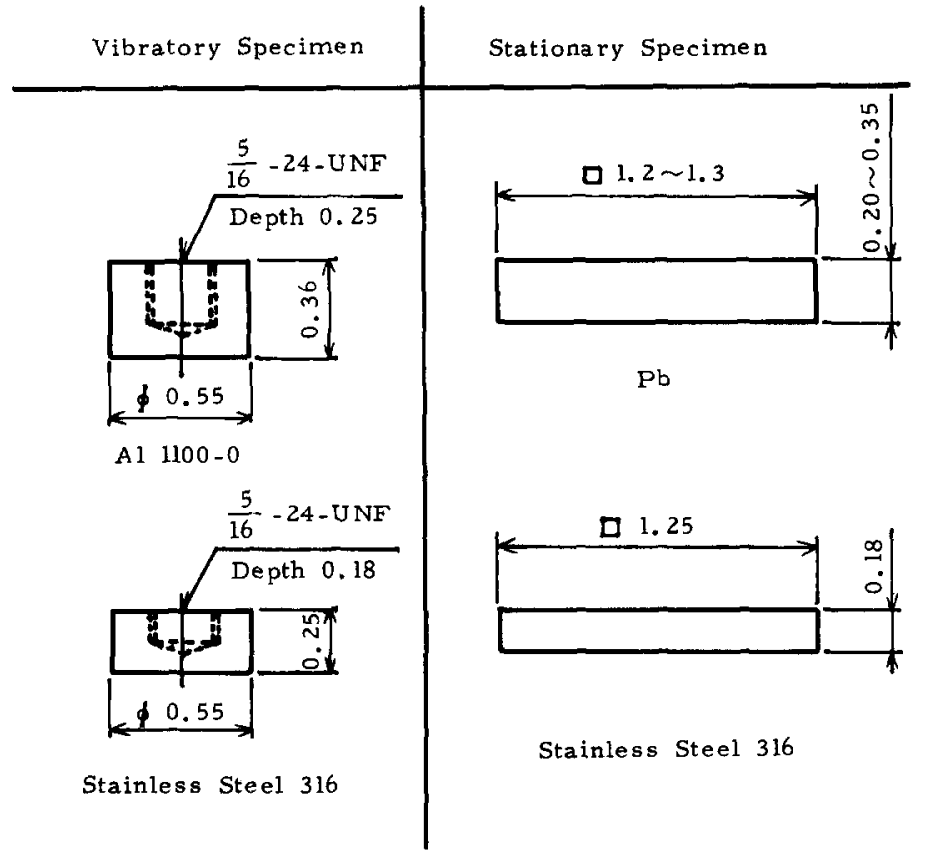

Fig. 3. Test specimens (dimensions in inches).

\subsection{Experimental procedure}

The vibratory facility was calibrated using a photonic sensor (model KD-38, Mechanical Technology Inc., Latham, NY) in air to verify the relation between horn amplitude and amplifier setting. These data were used to set horn amplitudes. The photonic sensor is a commercially available non-contact transducer for the measurement of displacement, which incorporated an optical system in an electronic circuit. The displacement 


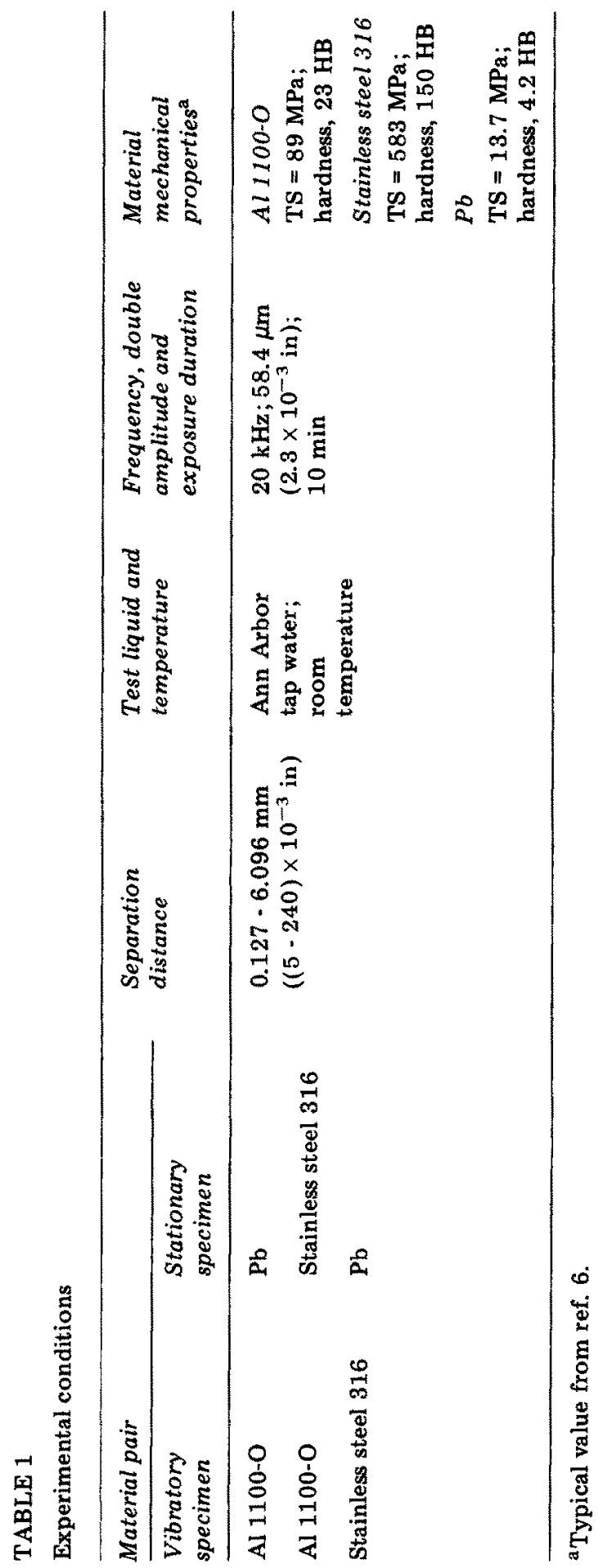


of the horn can be detected by the reflections of light incident from the photonic sensor to the vibrating surface. The reflected light generates an electrical output proportional to the displacement. Figure 4(a) shows the relation between displacement and output voltages. The front slope was very suitable for us to measure small displacements precisely. Figure 4(b) is a photograph of the calibration set-up. Tap water (the test liquid) was

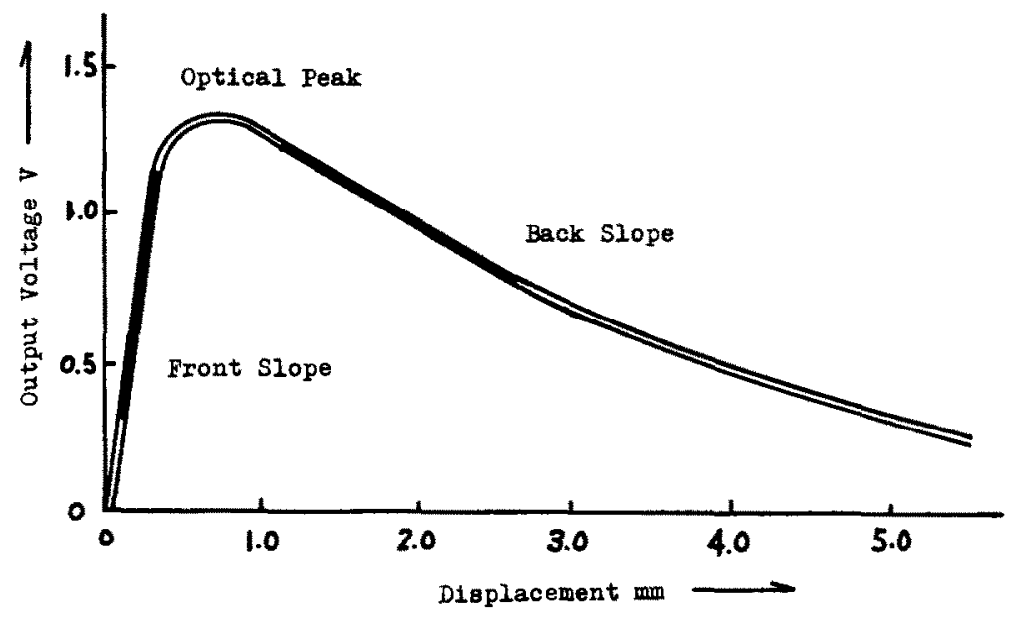

(a)

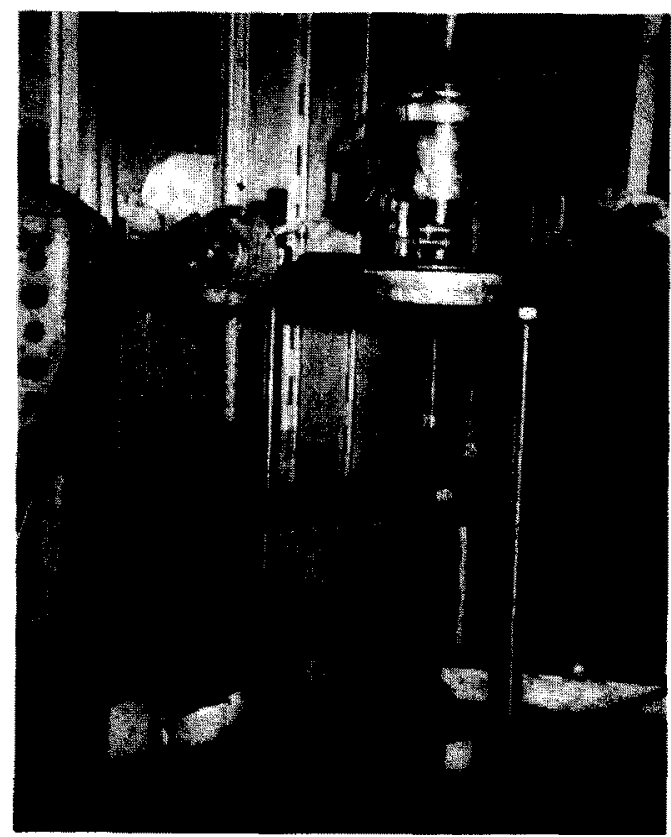

(b)

Fig. 4. (a) Output characteristics of the photonic sensor; (b) calibration set-up. 
allowed to stand in an open atmosphere for at least $24 \mathrm{~h}$ prior to all tests to stabilize the gas contents and to release entrained gases. The bulk water temperature was approximately ambient temperature (about $21^{\circ} \mathrm{C}$ ), but the water temperature was measured near the horn during tests since the local water temperature near the horn rises in this type of close-clearance test (see for example refs. 1 and 2).

Prior to the tests, all specimens were polished with grade 600 sandpaper, and weighed (mass accuracy, $\pm 0.01 \mathrm{mg}$ ) before and after each $10 \mathrm{~min}$ test. The separation distance between vibratory and stationary specimens was varied by shims (Fig. 1), to $\pm 25 \mu \mathrm{m}$ accuracy. For all tests, vibratory specimens were immersed in the water to a depth of about $6 \mathrm{~mm}$, and the system was driven at its resonant frequency (about $20 \mathrm{kHz}$ ) by a $250 \mathrm{~W}$ amplifier.

\section{Experimental results and discussion}

\subsection{Results}

Figure 5 shows the mass loss as a function of separation distance between vibratory and stationary specimens for the three material pairs. The stainless steel 316 specimens had no measurable mass loss (less than $0.1 \mathrm{mg}$ ) for the $10 \mathrm{~min}$ tests. Figure 6 shows the water temperature rise $\Delta T$ versus separation distance $L . \Delta T$ substantially ranges from about 5 to about $18{ }^{\circ} \mathrm{C}$ as the separation distance is decreased. This trend is, of course, to be expected.

\subsection{Discussion}

3.2.1. Energy conservation in a cavitation field

In this experiment it can be assumed that energy emitted to the fluid by the vibratory specimen is approximately constant, irrespective of specimen materials and separation distance. This energy is transferred from the vibratory specimen to the liquid, and then from the liquid to both specimens, by the cavitating field. For the most part, this energy causes a significant temperature rise of the liquid in the enclosed geometry between specimens. A much smaller portion of the energy is absorbed by both specimens, and this also results in some erosion. The cavitation specimen mass loss can then be considered as an index indicating the energy consumed by the erosion. We have previously called the ratio between erosion and acoustic power the "cavitation erosion efficiency" $\eta_{\text {CAV }}$ (see for example refs. 7 and 8 ). $\eta_{\mathrm{CAV}}$ was found to be very small (about $10^{-8} \cdot 10^{-12}$ ) $[7,8]$ and variable depending on conditions.

The aluminum vibratory specimen mass loss (Fig. 5) indicates quite complex results, which depend also on the stationary specimen material. For the aluminum-stainless steel pair, WL for the vibratory aluminum specimen is more than for the aluminum-lead pair. This may indicate that very little energy is absorbed in the relatively hard stainless steel specimen, at least compared with the much softer lead. 


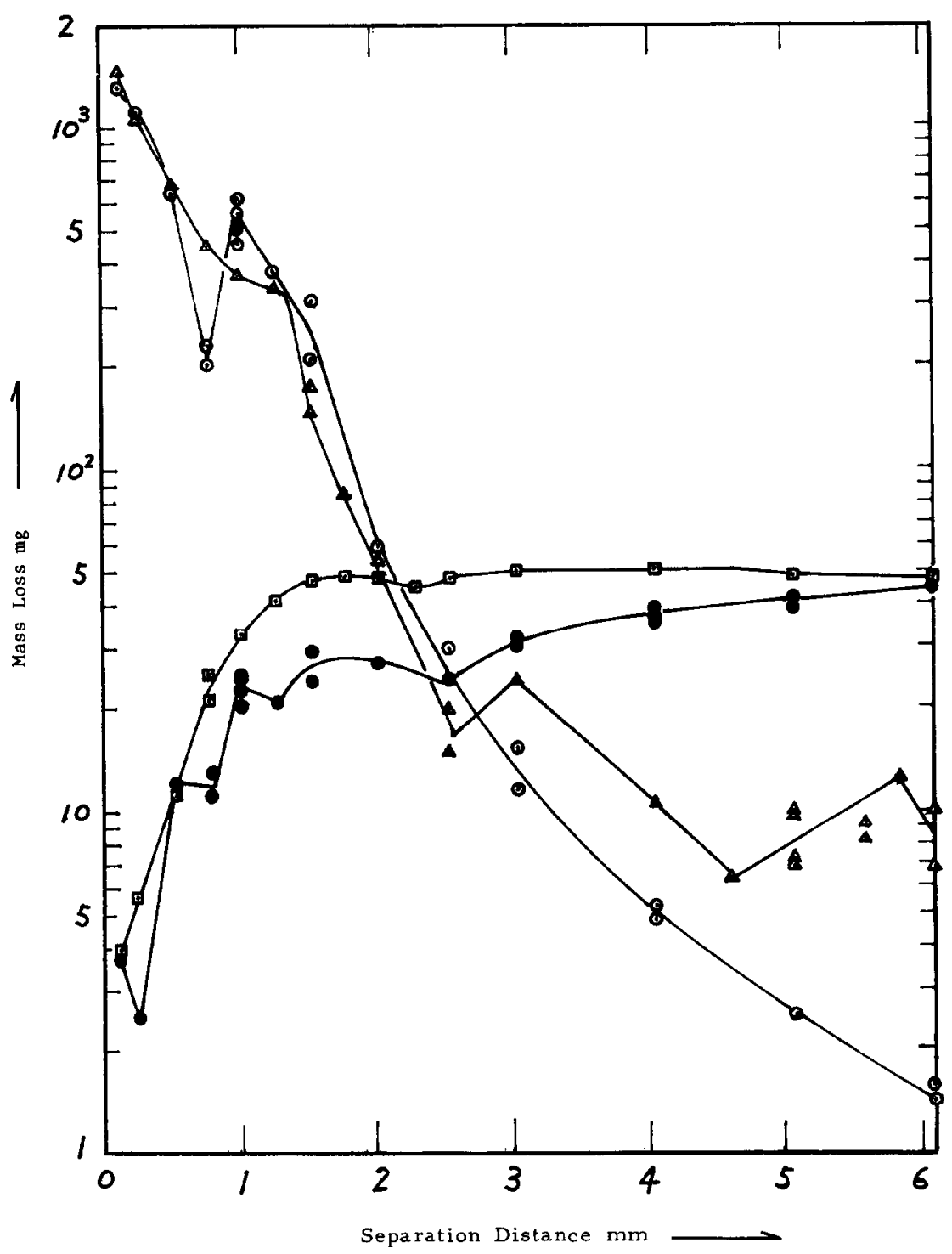

Fig. 5. Relation between mass loss and separation distance for the pairs aluminum-lead $(\bullet$, vibratory aluminum specimen; $\odot$, stationary lead specimen), stainless steel-lead $(\Delta$, stationary lead specimen) and aluminum-stainless steel (๑, vibratory aluminum specimen).

Figures 7 and 8 show the relation of $\mathrm{WL} / \mathrm{WL}_{\max }$ to $L / L_{\max } . \mathrm{WL}_{\max }$ (the maximum mass loss in 10 min test, which depends on separation distance and material pair) of the vibratory aluminum specimens occurs at different distances, depending on material pair. 


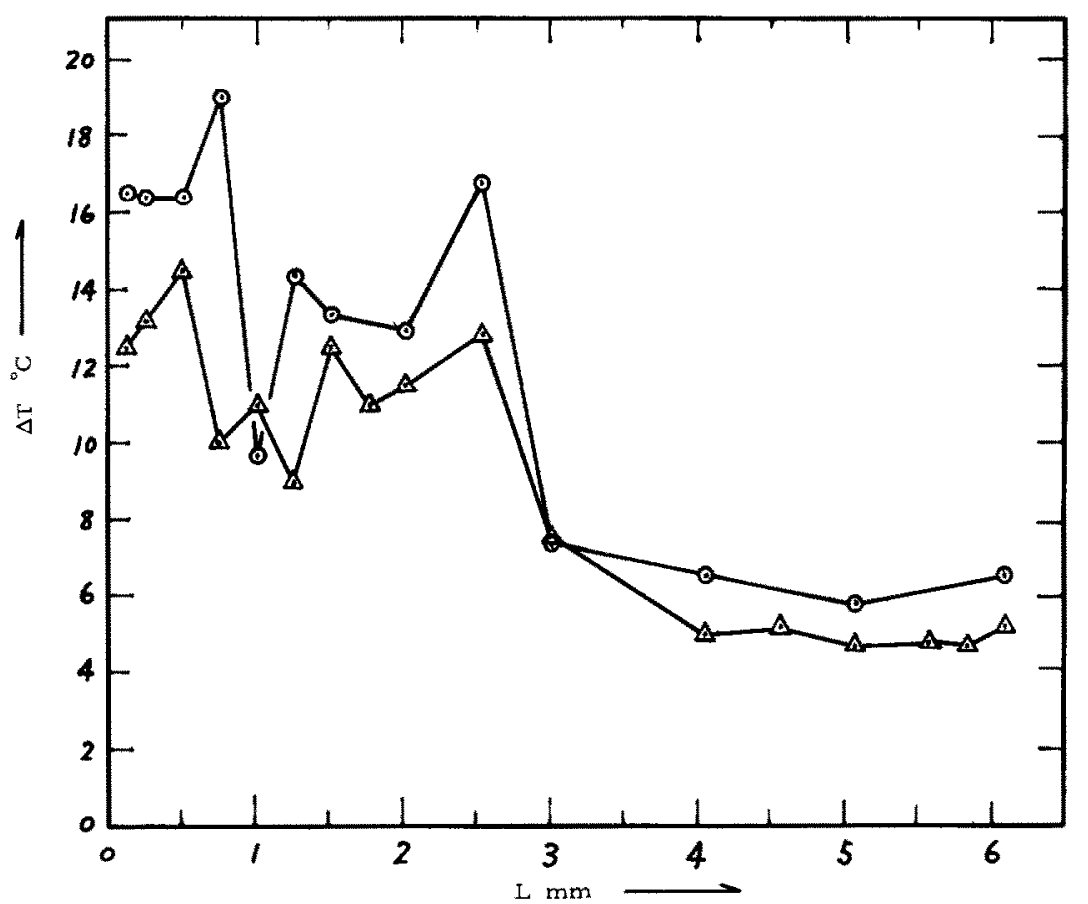

Fig. 6. Relation between $\Delta T$ and $L$ for aluminum-lead $(\odot)$ and stainless steel-lead $(\Delta)$ pairs.

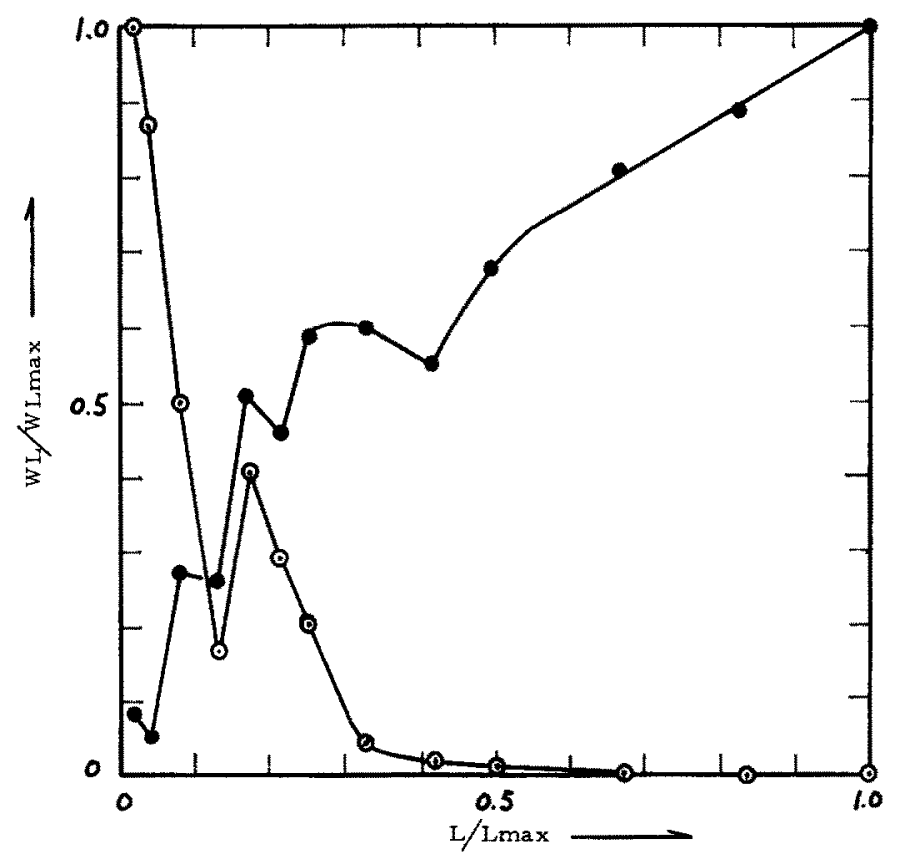

Fig. 7. Relation between $W L / W L_{\max }$ and $L / L_{\max }$ for the aluminum-lead pair: $\bullet$, vibratory aluminum specimen; $\odot$, stationary lead specimen. 


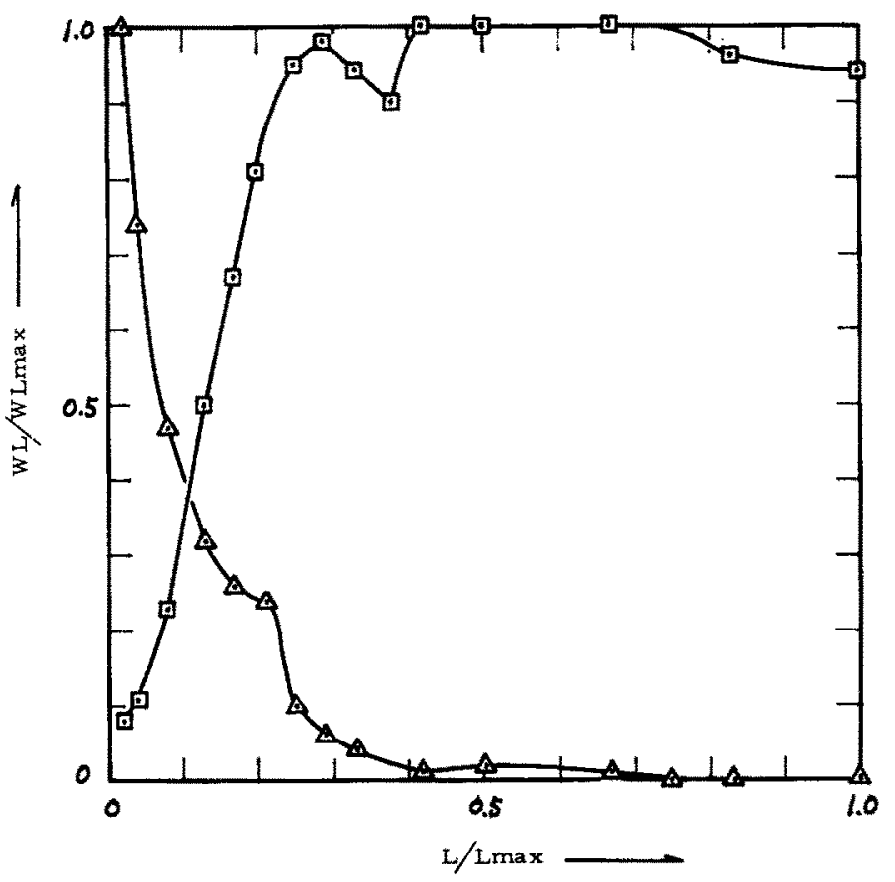

Fig. 8. Relation between $W L / W L_{\max }$ and $L / L_{\max }$ for the aluminum-stainless steel and stainless steel-lead pairs (vibratory and stationary stainless steel specimens show no measurable mass loss (less than $0.1 \mathrm{mg}$ )): $\square$, vibratory aluminum specimen; $\Delta$, stationary lead specimen.

For the aluminum-lead pair (Fig. 7), WL/WL $\mathrm{WLa}_{\max }$ for aluminum (vibratory specimen) increases in oscillating fashion as $L / L_{\max }$ is increased to the maximum. $W L / W L_{\max }$ reaches 1 at $L / L_{\max }=1$. In contrast, for the aluminum-stainless steel pair (Fig. 8), WL/WL $\mathrm{Wmax}_{\max }$ for aluminum (vibratory specimen) increases linearly with a steep slope for the first part of the curve and then reaches about 1 for $L / L_{\max }=0.3$, remaining at about 1.0 for higher values of $L / L_{\max }$. Thus $W L / W L_{\max } \approx 1$ for $L / L_{\max }>0.3$ for this case. It decreases slightly for $L / L_{\max }>0.7$. For lead (stationary) (Figs. 7 and 8), WL/WL $\mathrm{Wax}_{\max }$ starts to decrease for $L / L_{\max }=0.13-0.2$ and then approaches zero. No explanations for these particular results can be advanced at this time.

\subsubsection{Energy transfer to stationary specimens}

The present erosion results show that the energy transferred from a vibratory specimen to a stationary specimen increases, as would be expected, as the separation distance decreases. As a rough approximation, one could assume that this energy is proportional to the reciprocal of the separation distance. Figures 9 and 10 show these results for all the specimen pairs. 


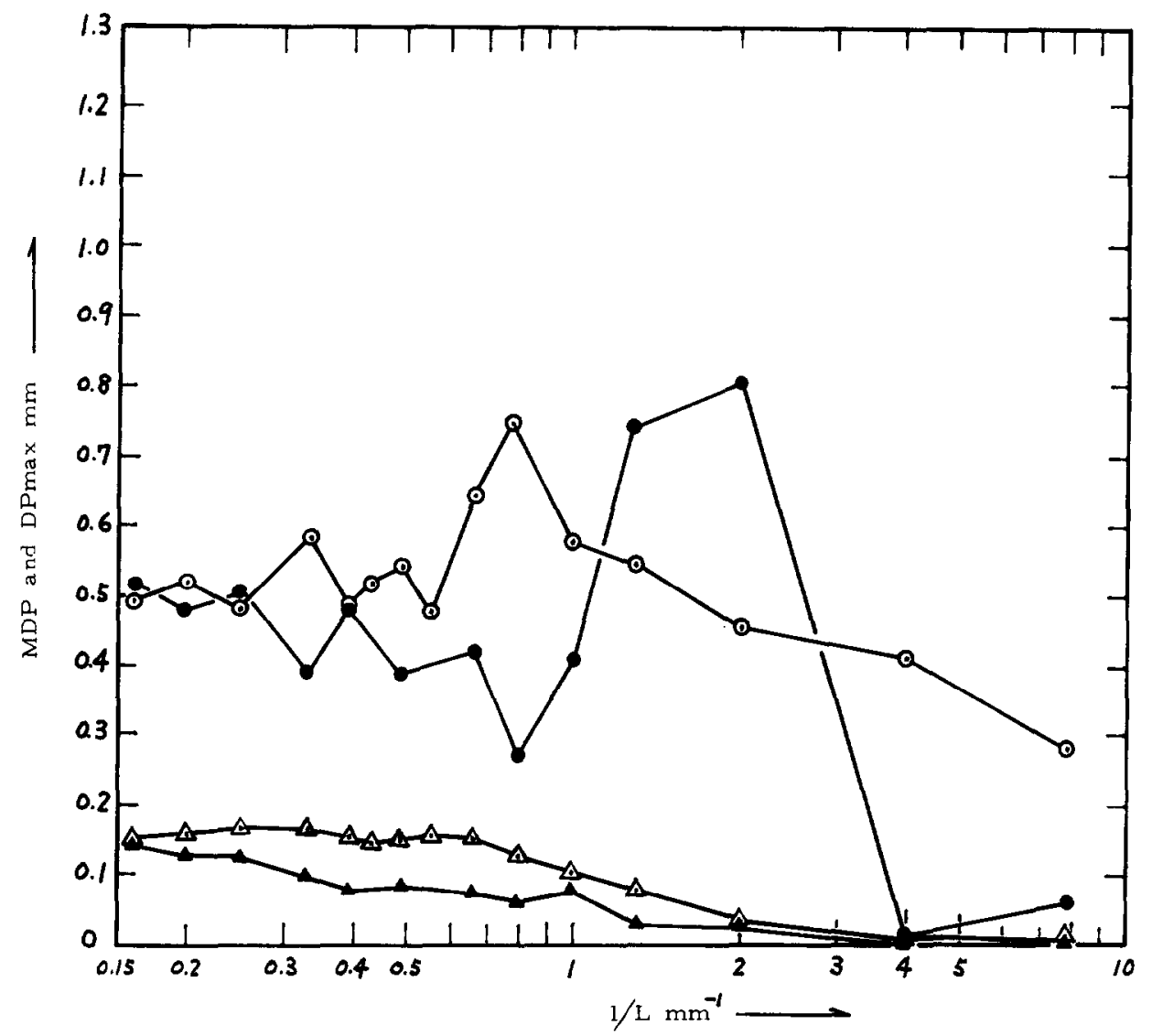

Fig. 9. $M D P$ and $D P_{\max }$ of vibratory aluminum specimens as a function of $1 / L$ for aluminum-stainless steel $(\Delta, \odot)$ and aluminum-lead $(\Delta, \bullet)$ pairs: $\triangle, \Delta, \mathrm{MDP} ; \odot, \bullet, \mathrm{DP}_{\max }-$

For the vibratory aluminum specimens (Fig. 9), MDP decreases continuously as $1 / L$ increases, but $\mathrm{DP}_{\max }$ reaches a maximum at $1 / L \approx 0.8$ $\mathrm{mm}^{-1}$ for the aluminum-stainless steel pairs and at about $2 \mathrm{~mm}^{-1}$ for the aluminum-lead pairs. For stationary lead specimens of the aluminum-lead pair (Fig. 10), MDP and $\mathrm{DP}_{\max }$ reach maxima at $1 / L=0.8-1.0 \mathrm{~mm}^{-1}$ and minima at $1 / L \approx 1.3 \mathrm{~mm}^{-1}$. For both material pairs, $\mathrm{MDP}$ and $\mathrm{DP}_{\max }$ increase continuously for $1 / L \tilde{>} 1.3 \mathrm{~mm}^{-1}$. The ratio $\mathrm{DP}_{\max } / \mathrm{MDP}$ is approximately constant. Thus the cavitation field obviously depends strongly on $1 / L$.

Figure 11 shows the temperature rise $\Delta T$ versus $1 / L$ for aluminumlead and stainless steel-lead pairs. The results for $\Delta T$ can be divided into three ranges: for $1 / L=0.16 \cdot 0.33 \mathrm{~mm}^{-1}, \Delta T=4.7-7.5^{\circ} \mathrm{C}$ (small fluctuations); for $1 / L=0.4-1.3 \mathrm{~mm}^{-1}, \Delta T=9.0-19.0^{\circ} \mathrm{C}$ (sharp fluctuations); for $1 / L=2.0-8.0 \mathrm{~mm}^{-1}, \Delta T=12.5-16.5^{\circ} \mathrm{C}$ (relatively constant). These 


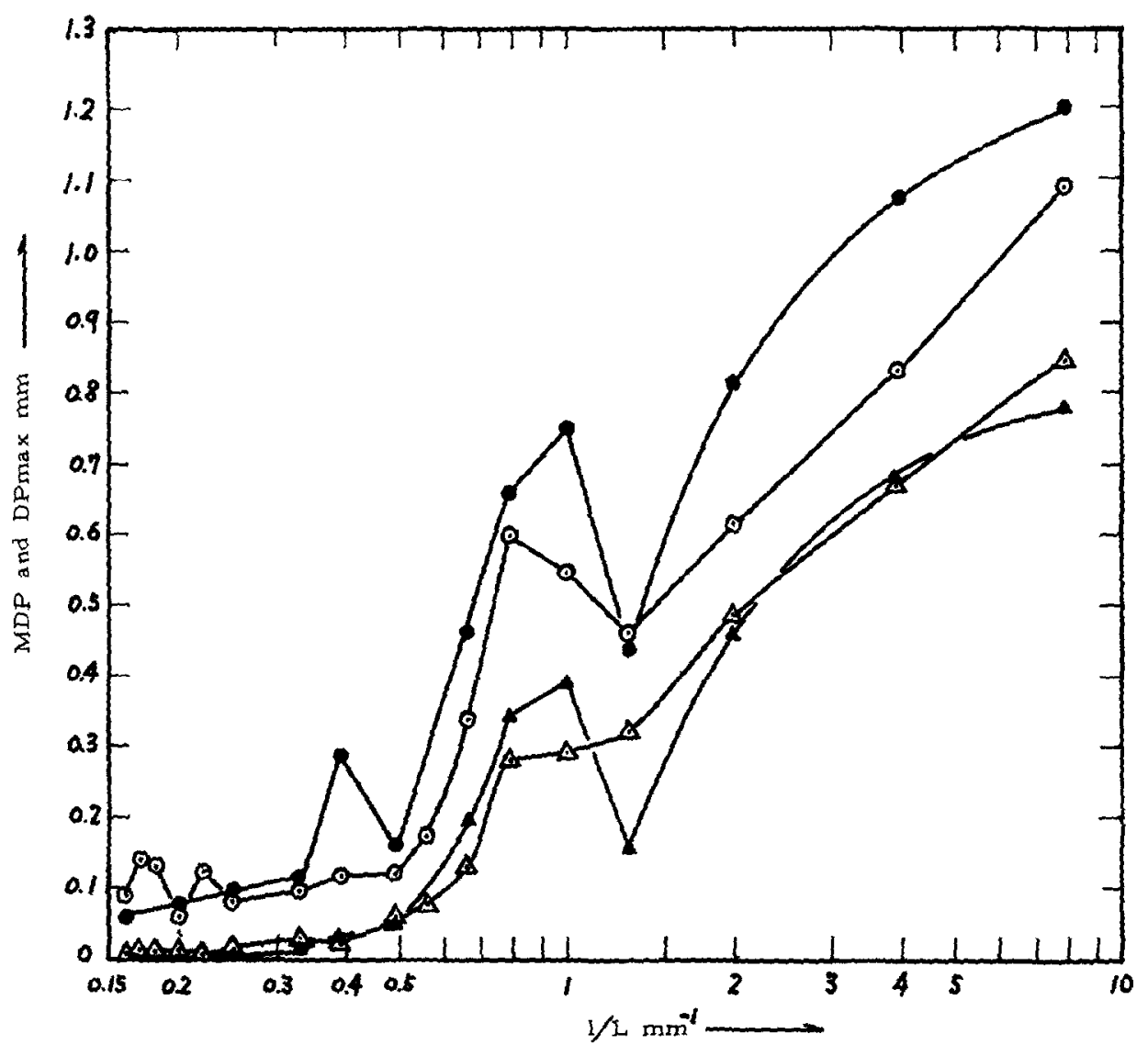

Fig. 10. MDP and $D P_{\max }$ of stationary lead specimens as a function of $1 / L$ for stainless steel-lead $(\Delta, 0)$ and aluminum-lead $(\Delta, \bullet)$ pairs : $\triangle, A, M D P ; O, \bullet, D P_{\max }$.

$\Delta T$ variations also indicate important changes in the cavitation field. In particular, $\Delta T$ sharply decreases at $1 / L=0.8 \mathrm{~mm}^{-1}$ (for the stainless steellead pair) and $1 / L=1.0 \mathrm{~mm}^{-1}$ (for the aluminum-lead pair) in spite of the increase in driving force for energy transfer. This means that the energy has been partially consumed by erosion. In fact, the maximum value of $\mathrm{DP}_{\max }$ of stationary lead specimens occurs at the same point, i.e. at $1 / L=$ $0.8 \mathrm{~mm}^{-1}$ and $1 / L=1.0 \mathrm{~mm}^{-1}$ (Fig. 10 ).

Figure 12 shows cavitation erosion patterns on stationary lead and vibratory aluminum specimens. For the stainless steel-lead pair, at $1 / L=$ $2.0 \mathrm{~mm}^{-1}$, the stationary lead specimen is eroded uniformly but, at $1 / \mathrm{L}=$ $0.33 \mathrm{~mm}^{-1}$, it has many pits and wrinkle-like deformations. For the aluminum-lead pair, two photographs of the stationary lead specimen correspond to the minimum and maximum values of MDP and $D P_{\max }$ (Fig. 10). It is seen that the stationary lead specimen at $1 / L=1.3 \mathrm{~mm}^{-1}$ 


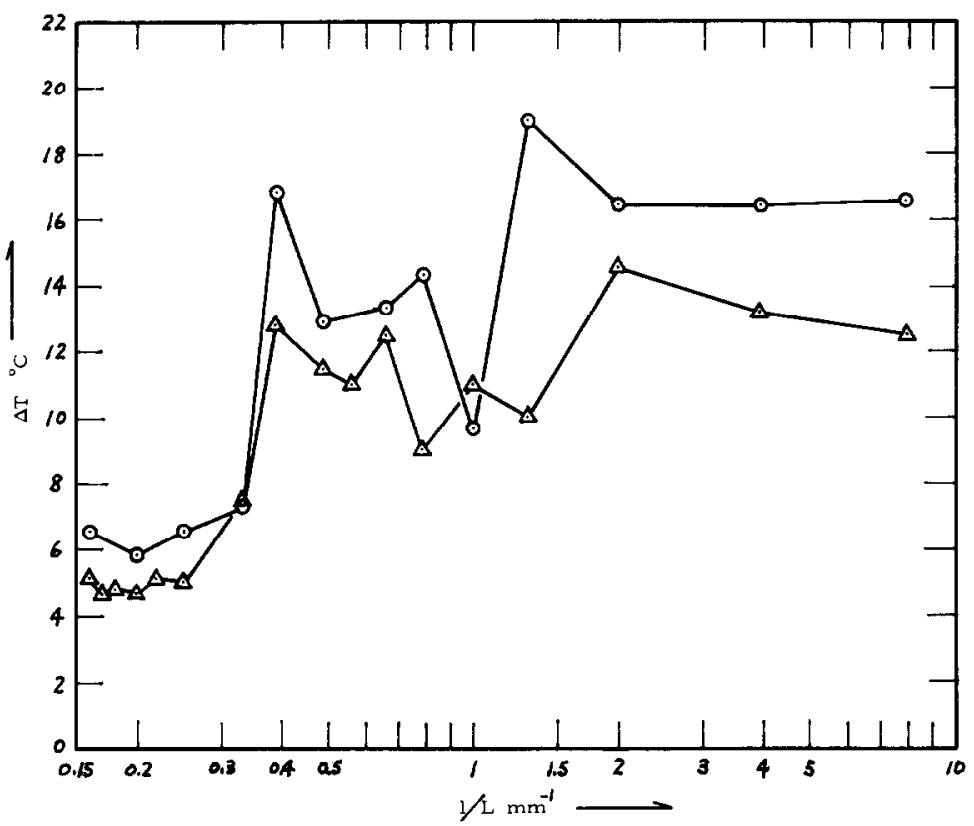

Fig. 11. Relation between $\Delta T$ and $1 / L$ for aluminum-lead $(\odot)$ and stainless steel-lead $(\triangle)$ pairs.

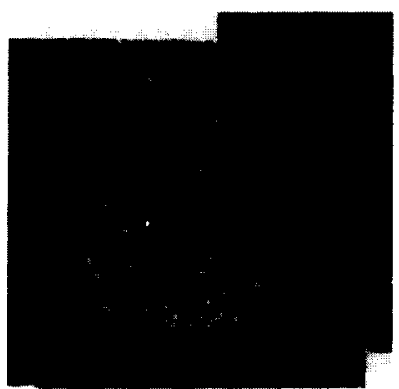

(a)

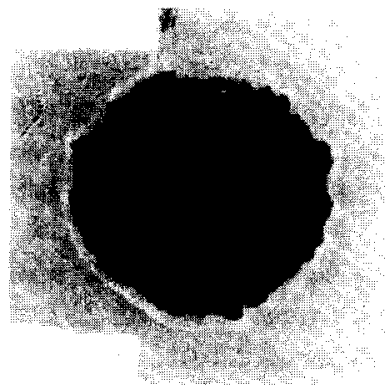

(d)

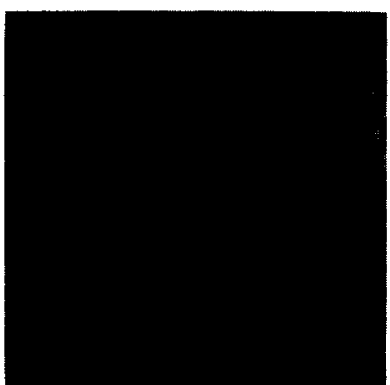

(b)

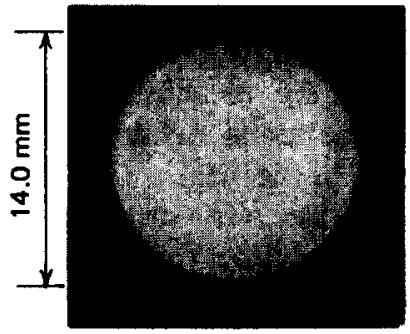

(e)

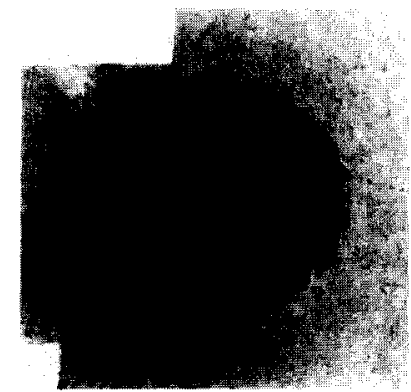

(c)

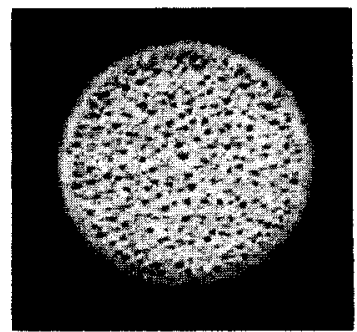

(f)

Fig. 12. Photographs of cavitation erosion patterns for (a), (b) stainless steel-lead ((a) $1 / L=2.0 \mathrm{~mm}^{-1}$; (b) $1 / L=0.33 \mathrm{~mm}^{-1}$ ) and (c) - (f) aluminum-lead ((c) $1 / L=1.3$ $\mathrm{mm}^{-1}$; (d) $1 / L=1.0 \mathrm{~mm}^{-1}$; (e) $1 / L=3.9 \mathrm{~mm}^{-1}$; (f) $1 / L=0.5 \mathrm{~mm}^{-1}$ ) pairs. 
does not have deep pits. This is similar to the aluminum specimen at $1 / L=$ $3.9 \mathrm{~mm}^{-1}$. These results indicate that violent cavitation on the stationary specimen no longer exists for $1 / L \geqslant 1.3 \mathrm{~mm}^{-1}$.

Figure 13 shows WL for stationary lead specimens as a function of $1 / L$ for aluminum-lead and stainless steel-lead pairs. Both curves suggest

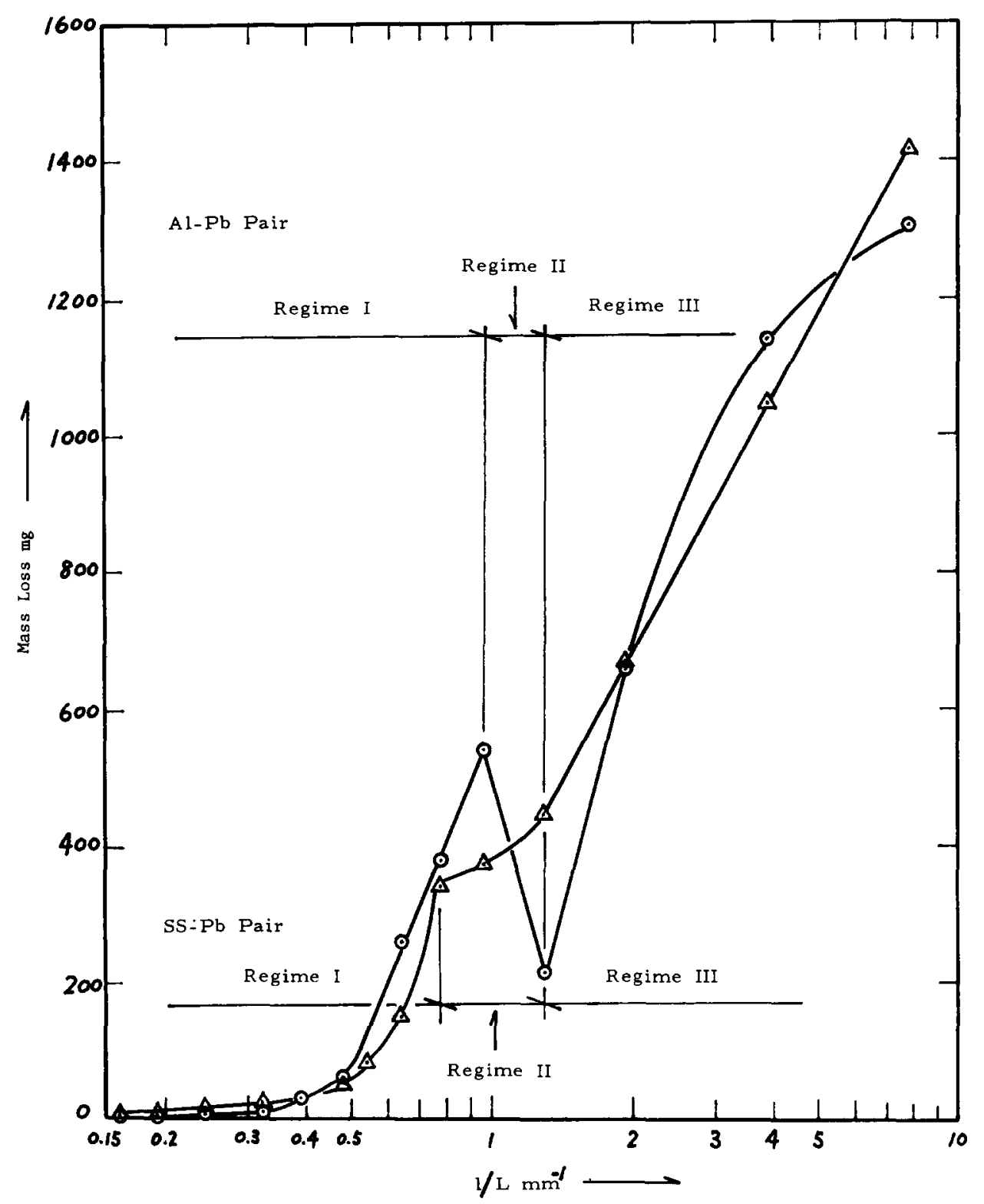

Fig. 13. WL of stationary lead specimen as a function of $1 / L$ for aluminum-lead $(\odot)$ and stainless steel-lead $(\Delta)$ pairs. 
that physical changes in the cavitation field are occurring for $1 / L=0.8$ $1.3 \mathrm{~mm}^{-1}$. Variations in $\mathrm{DP}_{\max }, \Delta T$ and cavitation found in the experiment suggest the same.

\section{Conclusions}

(1) The mass loss of both vibratory and stationary specimens depends substantially on the material pairs tested, i.e. there is a substantial interdependence between the materials. In particular for the aluminum-lead pair, the mass loss of vibratory aluminum specimens shows quite complex changes.

(2) The mass loss of stationary lead specimens is presented as a function of the reciprocal of separation distance. The resulting curve can be divided into three regimes from the viewpoint of energy transfer.

\section{Acknowledgments}

The authors are indebted to Mr. Bong-Hwa Sun, doctoral candidate, Mechanical Engineering Department, University of Michigan, for his help in this work, and to Messrs. Evans Wuu and Goutama Pinnamaneni, students, for their cooperation. The authors would also like to express their appreciation to Mr. Jack Brigham.

\section{References}

1 K. Endo, T. Okada and M. Nakashima, A study of exosion between two parallel surfaces oscillating at close proximity in liquid, J. Lubr. Technol, 89 (4) (1967) 15.

2 D. Brager, R. Cheesewright, F. G. Hammitt and D. J. Kemppainen, Cavitation erosion of a stationary specimen in close proximity to an oscillating surface, Tech. Rep. 08153-4-T, May 1967 (University of Michigan, Ann Arbor, MI).

3 D. J. Kemppainen and F. G. Hammitt, Effects of external stress on cavitation damage, Proc. 13th Congr. IAHR, August 1969, Kyoto, International Association for Hydraulic Research.

4 D. W. Parkins and R. May-Miller, Cavitation in an oscillatory oil squeeze film, ASMEASLE Joint Lubrication Conf,, Hartford, CT, October 18 - 20, 1983.

5 P. R. Scott, Cavitation resistance of rocks, Ph.D. Thesis, Department of Mining Engineering, University of Missouri-Rolla, Rolla, MO, 1979.

6 Metals Handbook, American Society for Metals, Metals Park, OH, 1961.

7 F. G. Hammitt, Cavitation and Multiphase Flow Phenomena, McGraw-Ilill, New York, 1980.

8 S. Hattori, B. H. Sun, F. G. Hammitt and T. Okada, An application of bubble collapse pulse height spectra to Venturi cavitation erosion of 1100-0 aluminum, Tech. Rep. UMICH 014571-69-I, July 1983 (University of Michigan, Ann Arbor, MI). 


\section{Appendix A: Nomenclature}

$\mathrm{DP}_{\max }$ maximum depth of penetration $(\mathrm{mm})$

$L \quad$ separation distance between vibratory and stationary specimens $(\mathrm{mm})$

MDP mean depth of penetration $(\mathrm{mm})$; equivalent to volume loss per unit eroded area

$\Delta T \quad$ temperature rise of test liquid $\left({ }^{\circ} \mathrm{C}\right)$

TS tensile strength (MPa)

WL mass loss (mg) 